SUBJECT AREAS:

CROHN'S DISEASE

ULCERATIVE COLITIS

MALNUTRITION

PAEDIATRIC RESEARCH

Received

13 December 2013

Accepted

17 March 2014

Published

24 April 2014

Correspondence and requests for materials should be addressed to

J.W. (jarwalk@ump. edu.pl) \title{
deficiency in children with inflammatory bowel disease
}

\author{
Jan K. Nowak', Urszula Grzybowska-Chlebowczyk², Piotr Landowski ${ }^{3}$, Anna Szaflarska-Poplawska ${ }^{4}$, \\ Beata Klincewicz' ${ }^{1}$ Daria Adamczak ${ }^{5}$, Tomasz Banasiewicz ${ }^{6}$, Andrzej Plawski \& Jaroslaw Walkowiak'
}

\begin{abstract}
'Poznan University of Medical Sciences, Department of Pediatric Gastroenterology and Metabolic Diseases, Poznan, Poland, ${ }^{2}$ Medical University of Silesia, Department of Paediatrics, Katowice, Poland, ${ }^{3}$ Medical University of Gdansk, Department of Pediatrics, Pediatric Gastroenterology, Hepatology and Nutrition, Gdansk, Poland, ${ }^{4}$ Nicolaus Copernicus University, Ludwik Rydygier Collegium Medicum in Bydgoszcz, Department of Pediatric Endoscopy and Gastrointestinal Function Testing, Bydgoszcz, Poland, ${ }^{5}$ Poznan University of Medical Sciences, Poznan, Poland, 'Poznan University of Medical Sciences, Department of General, Gastroenterological and Endocrinological Surgery, Poznan, Poland, 'Institute of Human Genetics, Polish Academy of Sciences, Poznan, Poland.
\end{abstract}

Although vitamin $\mathrm{K}$ deficiency has been implicated in adult inflammatory bowel disease (IBD), its prevalence in pediatric IBD remains unknown. We carried out a cross-sectional study in 63 children with Crohn's disease (CD) and 48 with ulcerative colitis (UC) to assess the prevalence of vitamin K deficiency and to search for potential correlation between vitamin $\mathrm{K}$ status and pediatric IBD activity. Vitamin $\mathrm{K}$ status was assessed using protein induced by vitamin $\mathrm{K}$ absence-II (PIVKA-II; ELISA). Prevalence of vitamin K deficiency was $54.0 \%$ in CD and $43.7 \%$ in UC. Vitamin K deficiency was more common in patients with higher CD activity, in CD patients with higher mass Z-scores, and less common among children with CD treated with infliximab. Relation of vitamin K deficiency to pediatric IBD clinical course and treatment demand further research.

$\mathrm{V}$ itamin $\mathrm{K}$ is as a group of molecules serving as cofactors of protein carboxylation that leads to creation of gamma-carboxyglutamic acid residues which enable calcium bonding ${ }^{1}$. Several vitamin K-dependent proteins are known. They are involved in coagulation, preservation of bone mineral density and protection against vascular calcification ${ }^{2,3}$. It is also postulated that vitamin $\mathrm{K}$ plays an important role in the central nervous system $^{4}$. Thus, vitamin $\mathrm{K}$ deficiency has a range of consequences, of which loss of bone mineral density is the most prominent, as it manifests even before blood coagulation factors production becomes altered ${ }^{5}$.

One of two main substrates of vitamin K-dependent carboxylation used for vitamin $\mathrm{K}$ status assessment is protein induced by vitamin K absence-II (PIVKA-II), the other being osteocalcin ${ }^{6}$. Plasma PIVKA-II concentrations were shown to inversely correlate with plasma phylloquinone concentrations ${ }^{7}$. PIVKA-II levels assessment and direct vitamin $\mathrm{K}$ concentrations measurements have shown that vitamin $\mathrm{K}$ deficiency is prevalent in patient populations as different as newborn infants ${ }^{8}$, children with chronic liver disease ${ }^{9}$, hemodialyzed patients ${ }^{10}$, cystic fibrosis patients ${ }^{11,12}$, the institutionalized elderly ${ }^{13}$, and is also a consequence of treatment with vitamin $\mathrm{K}$ antagonists ${ }^{14}$. Vitamin $\mathrm{K}$ deficiency has also been reported in chronic gastrointestinal disorders ${ }^{15}$, including inflammatory bowel diseases (IBD) $)^{16,17}$. However, to authors' best knowledge, vitamin $\mathrm{K}$ status has not been investigated in children with IBD so far.

The aim of this study was to assess the prevalence of vitamin $\mathrm{K}$ deficiency and its correlates in children with Crohn's disease (CD) and ulcerative colitis (UC).

\section{Results}

The median PIVKA-II serum concentration [interquartile range] in IBD equaled $2 \mathrm{ng} / \mathrm{mL}$ [1.3-3.1]; it was 2.3 [1.3-3.5] in Crohn's disease, and 1.9 [1.3-2.7] in ulcerative colitis. PIVKA-II levels were equal to or higher than $2 \mathrm{ng} / \mathrm{mL}$ in 34 of 63 patients (54.0\%) with CD and 21 of 48 patients (43.7\%) with UC. Basic clinical features in CD and UC patients with and without vitamin K deficiency are shown in Tables 1 and 2, respectively. The PCDAI and Truelove-Witts scores in patients with and without vitamin K deficiency are illustrated in Fig. 1. 
Table 1 | Basic clinical features in Crohn's disease patients with and without vitamin $\mathrm{K}$ deficiency.

Vitamin K deficiency

Variables

Median [ $1^{\text {st- }} 3^{\text {rd }}$ quartiles $]$ or percentage

Number of patients
Age (years)
Body mass (Z-score)
Height (Z-score)
Disease duration (months)
lleal involvement

Pediatric Crohn's Disease

Activity Index score

C-reactive protein serum

concentration relative to cutoff value

Hospitalizations

Exacerbations

Corticosteroid treatment

Immunosuppressive treatment

Infliximab

\begin{tabular}{|c|c|c|}
\hline \multicolumn{2}{|c|}{ Vitamin K deficiency } & \multirow{3}{*}{$p$-value } \\
\hline \multicolumn{2}{|c|}{ Median $\left[1^{\text {st- }} 3^{\text {rd }}\right.$ quartiles $]$ or percentage } & \\
\hline No & Yes & \\
\hline $\begin{array}{c}29(46.0 \%) \\
15.0[12.0-16.2] \\
-\mathbf{1 . 1}[-\mathbf{1 . 5}-(-\mathbf{0 . 5})] \\
-0.4[-1.0-0.2] \\
19.0[7.0-27.0] \\
75.9 \% \\
\mathbf{1 5 . 0}[\mathbf{1 0 . 0}-\mathbf{2 5 . 0}]\end{array}$ & $\begin{array}{c}34(54.0 \%) \\
16.0[14.0-17.0] \\
-\mathbf{0 . 4}[-\mathbf{1 . 3 - 0 . 0}] \\
-0.3[-0.9-0.3] \\
15.5[6.2-33.5] \\
84.8 \% \\
\mathbf{2 2 . 5}[\mathbf{1 0 . 6 - 5 0 . 0}]\end{array}$ & $\begin{array}{l}0.19 \\
\mathbf{0 . 0 4} \\
0.41 \\
0.59 \\
0.57 \chi^{2} \\
\mathbf{0 . 0 4}\end{array}$ \\
\hline $1.2[0.5-3.1]$ & $1.5[0.4-2.7]$ & 0.71 \\
\hline $\begin{array}{c}1.0[0.5-2.0] \\
1.0[1.0-2.0] \\
34.5 \% \\
58.6 \% \\
\mathbf{3 4 . 5} \% \\
(10 \text { out of } 29)\end{array}$ & $\begin{array}{c}1.5[1.0-2.0] \\
1.0[0.25-2.0] \\
55.9 \% \\
55.9 \% \\
11.8 \% \\
(4 \text { out of } 34)\end{array}$ & $\begin{array}{l}0.68 \\
0.84 \\
0.09 \chi^{2} \\
0.93 \chi^{2} \\
\mathbf{0 . 0 3} \chi^{2}\end{array}$ \\
\hline
\end{tabular}

The prevalence of vitamin K deficiency was $28.6 \%$ in children with $\mathrm{CD}$ receiving infliximab and $61.2 \%$ in children with $\mathrm{CD}$ not receiving biological therapy $\left(\chi^{2}, \mathrm{p}=0.03\right)$. The median PCDAI scores in CD patients receiving infliximab and in children not treated with infliximab did not differ (14.5 [12.5-17.5] and 20.0 [10.0-42.5], respectively). Significant differences in body mass Z-scores of vitamin $\mathrm{K}$-sufficient and vitamin K-deficient $\mathrm{CD}$ patients were also noted $(\mathrm{p}=0.04)$.

Higher prevalence of vitamin $\mathrm{K}$ deficiency in $\mathrm{CD}$ patients treated with corticosteroids was statistically non-significant $\left(\chi^{2}, \mathrm{p}=0.09\right)$. Body mass Z-score values in vitamin $\mathrm{K}$-deficient children with UC were not significantly lower than in vitamin K-sufficient children with UC $(\mathrm{p}=0.07)$.

PIVKA-II levels positively correlated with PCDAI scores $(\sigma=$ $0.37, \mathrm{p}=0.03$ ). PIVKA-II concentrations did not correlate with longer CD duration $(\sigma=-0.22, \mathrm{p}=0.08)$ and patients' body mass $\mathrm{Z}$-scores $(\sigma=0.17, \mathrm{p}=0.18)$. No variables correlated with PIVKAII levels in children with UC.

In univariate logistic regression models the probability of vitamin $\mathrm{K}$ deficiency increased with higher PCDAI scores (OR $=1.04,95 \%$ CI 1.01-1.07, $\mathrm{p}=0.02)$. Similarly, higher body mass Z-scores predicted vitamin $\mathrm{K}$ deficiency in children with $\mathrm{CD}(\mathrm{OR}=1.64,95 \% \mathrm{CI}$ $1.01-2.65, \mathrm{p}=0.04)$. For all other continuous variables analyzed $\mathrm{p}$ was 0.09 or greater. Multiple regression analyses in CD and UC did not yield any significant results ( $\mathrm{p} \geq 0.10$ for all factors).

\section{Discussion}

This is the first study to document vitamin $\mathrm{K}$ deficiency in pediatric IBD population. Every second IBD patient was vitamin K-deficient. Vitamin $\mathrm{K}$ deficiency was more common in CD than in UC. This finding is consistent with results previously obtained in adults. However, the data obtained in this study suggest that vitamin $\mathrm{K}$ deficiency could be more frequent in children with UC than in adults with UC. The percentage of patients with undercarboxylated osteocalcin levels above cutoff value reported in a report by Kuwabara et al. ${ }^{16}$ was $92 \%$ in $\mathrm{CD}(\mathrm{N}=47)$ and $36 \%$ in UC patients $(\mathrm{N}=40)$. Nakajima et al. ${ }^{17}$ who investigated a group of $47 \mathrm{CD}$ patients, $40 \mathrm{UC}$ patients and 41 healthy volunteers found higher undercarboxylated osteocalcin levels in CD patients and no evidence of vitamin K deficiency in adults with UC. Vitamin K deficiency in adult IBD patients was also described by Krasinski et al. They reported high PIVKA-II concentrations in 13 out of 34 patients with $\mathrm{CD}$ and in 4 out of 17 patients with $\mathrm{UC}^{15}$.

The reason for vitamin $\mathrm{K}$ deficiency in IBD remains unclear. It may be hypothesized that vitamin $\mathrm{K}$ deficiency results from undernutrition and/or malabsorption caused by IBD and utilized

Table 2 | Basic clinical features in ulcerative colitis patients with and without vitamin $\mathrm{K}$ deficiency.

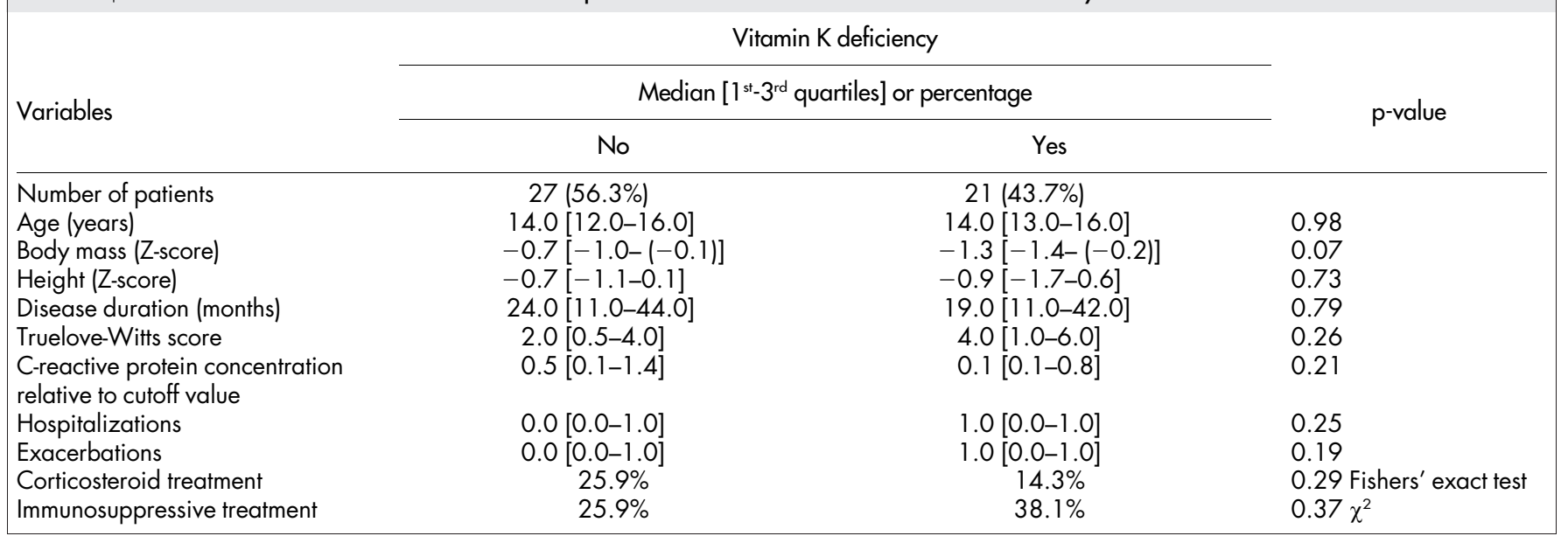



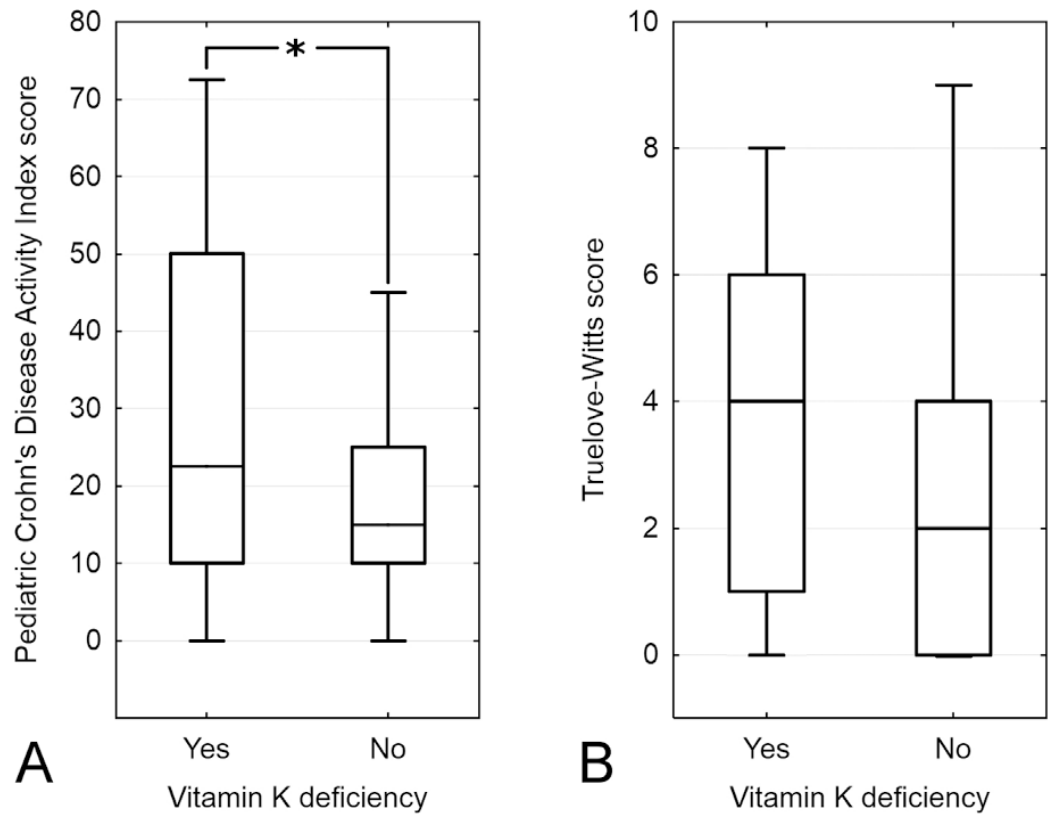

Figure $1 \mid$ The Pediatric Crohn's Disease Activity Index (A) and Truelove-Witts (B) scores in children with and without vitamin K deficiency. Median values, 1 st and 3rd quartiles, as well as the minimum and maximum values are shown. The asterisk denotes statistical significance $(\mathrm{p}=0.04)$.

treatments. This notion is supported by the evidence for vitamin $\mathrm{E}$ co-deficiency in $\mathrm{IBD}^{14}$ and for antibiotic-induced vitamin $\mathrm{K}$ metabolism disturbance ${ }^{18-20}$. Shea et al. pointed out that vitamin $\mathrm{K}$ may have anti-inflammatory properties ${ }^{21}$. Given this assumption is true, vitamin $\mathrm{K}$ deficiency should lead to a more severe IBD course and, consequently, more pronounced undernutrition and malabsorption. Indeed, PCDAI scores positively correlated with PIVKA-II levels, indicating greater prevalence of vitamin $\mathrm{K}$ deficiency in patients with more active CD. Although the results obtained do not seem to lend support to the hypothesis that vitamin $\mathrm{K}$ deficiency plays a causative role in the pathogenesis of IBD, it needs to be underscored that this is a separate question that the study presented did not address.

Vitamin K deficiency was less common in patients receiving infliximab. This fact points to a possibility that vitamin $\mathrm{K}$ status in $\mathrm{CD}$ reflects the intensity of inflammation. Further research is needed to clarify whether biological therapy influences vitamin $\mathrm{K}$ status in children with Crohn's disease. In fact, no studies on the relationship between anti-TNF therapies and vitamin $\mathrm{K}$ status have been published so far.

It is interesting that while body mass Z-scores of vitamin K-deficient children with $C D$ were higher compared to those who were vitamin $\mathrm{K}$-sufficient, body mass $\mathrm{Z}$-scores in vitamin $\mathrm{K}$-deficient patients with UC were lower than in those who were vitamin $\mathrm{K}$ sufficient. The reasons for higher Z-scores in vitamin K-deficient patients with CD remain unclear.

The study was limited in several aspects. Firstly, vitamin K status was not analyzed directly. It remains an open question if direct measurement of vitamin $\mathrm{K}$ concentration in the blood would be more clinically relevant than the measurement of PIVKA-II concentration. Different vitamin $\mathrm{K}$ levels may lead to vitamin $\mathrm{K}$ sufficiency in different patients. Thus, the estimation of vitamin $\mathrm{K}$ status using PIVKA-II concentrations may present an advantage in that it reflects a lack of vitamin $\mathrm{K}$ cofactory function enabling for carboxylation of vitamin $\mathrm{K}$-dependent compounds. However, there are factors other than vitamin $\mathrm{K}$ status that influence PIVKA-II concentration and it cannot be ruled out that they are linked to IBD activity.

The cross-sectional character of the study did not allow for analysis of PIVKA-II concentrations' evolution along with disease activity changes. No data on dietary intake of vitamin K were available. If there are seasonal variations of vitamin $\mathrm{K}$ status, they could have been a source of bias, as the patients were examined at different time points.

Vitamin K deficiency was highly prevalent in pediatric IBD. In CD patients it correlated with a lack of infliximab treatment, a higher pediatric CD activity, and higher body mass Z-scores. Relation of vitamin $\mathrm{K}$ deficiency to pediatric IBD clinical course and treatment demand further research.

\section{Methods}

A total of 111 children with inflammatory bowel disease (IBD) were included in the study (67 M, 44 F, age range 6-18). Sixty-three were treated for CD and 48 for UC. Diagnoses were established on the basis of clinical, histological, endoscopic and/or radiographic criteria ${ }^{22-25}$. The inclusion criteria were: $\mathrm{CD}$ or UC diagnosed according to the aforementioned standards, and age of 18 years at most. The exclusion criteria were: liver disease not related to IBD, cancer, anti-vitamin K treatment, pregnancy, and diagnosis of AIDS.

Information on age, body mass and height, disease activity and duration, $\mathrm{C}$ reactive protein $(\mathrm{CRP})$ serum concentration, the number of hospitalizations for IBD, the number of IBD exacerbations, and the treatment in use were gathered using a questionnaire distributed among clinicians participating in the study. Disease activity in $\mathrm{CD}$ and UC was described using the Pediatric Crohn's Disease Activity Index $(\mathrm{PCDAI})^{25}$ and Truelove-Witts scores ${ }^{26}$, respectively. Z-scores for body mass and height were calculated using data relating to the local population ${ }^{27}$.

Vitamin K status was assessed using PIVKA-II concentration in patients' blood sera. PIVKA-II concentrations were determined by enzyme immunoassay

(Asserachrom PIVKA-II, Roche Diagnostic, Rotkreuz, Switzerland). It was considered that values $\geq 2 \mathrm{ng} / \mathrm{mL}$ (detectable values) indicated vitamin $\mathrm{K}$ deficiency $\mathrm{y}^{9,28}$.

Statistical analyses were performed in the R environment (version 2.14.1; The R Foundation for Statistical Computing, Vienna, Austria) and using STATISTICA 10 (StatSoft Inc., Tulsa, USA). Wilcoxon rank sum test was used to compare subgroups of $\mathrm{CD}$ and $\mathrm{CU}$ patients who were vitamin K sufficient and vitamin $\mathrm{K}$ deficient. Results obtained from logistic regression analysis, multiple regression analysis, Spearman's correlation test, Pearson's chi-squared test and Fisher's exact test are appropriately labeled. The level of significance was set at $\mathrm{p}<0.05$.

The study was conducted in accordance with the Declaration of Helsinki. Informed and written consent was obtained from patients' parents and patients who were at least 16 years old. The study design was approved by Poznan University of Medical Sciences Bioethical Committee, Poznan, Poland (decision no 53/11).

1. Krzyżanowska, P. et al. Vitamin K status in patients with short bowel syndrome. Clin. Nutr. Edinb. Scotl. 31, 1015-1017 (2012).

2. Cranenburg, E. C. M., Schurgers, L. J. \& Vermeer, C. Vitamin K: the coagulation vitamin that became omnipotent. Thromb. Haemost. 98, 120-125 (2007).

3. Theuwissen, E., Smit, E. \& Vermeer, C. The role of vitamin K in soft-tissue calcification. Adv. Nutr. Bethesda Md 3, 166-173 (2012). 
4. Ferland, G. Vitamin K and the nervous system: an overview of its actions. $A d v$. Nutr. Bethesda Md 3, 204-212 (2012).

5. McCann, J. C. \& Ames, B. N. Vitamin K, an example of triage theory: is micronutrient inadequacy linked to diseases of aging? Am. J. Clin. Nutr. 90, 889-907 (2009).

6. Gundberg, C. M., Lian, J. B. \& Booth, S. L. Vitamin K-dependent carboxylation of osteocalcin: friend or foe? Adv. Nutr. Bethesda Md 3, 149-157 (2012).

7. Sokoll, L. J. \& Sadowski, J. A. Comparison of biochemical indexes for assessing vitamin $\mathrm{K}$ nutritional status in a healthy adult population. Am. J. Clin. Nutr. 63, 566-573 (1996).

8. Chuansumrit, A. et al. Prevalence of subclinical vitamin K deficiency in Thai newborns: relationship to maternal phylloquinone intakes and delivery risk. Arch. Dis. Child. Fetal Neonatal Ed. 95, F104-108 (2010).

9. Mager, D. R., McGee, P. L., Furuya, K. N. \& Roberts, E. A. Prevalence of vitamin K deficiency in children with mild to moderate chronic liver disease. J. Pediatr. Gastroenterol. Nutr. 42, 71-76 (2006).

10. Stankowiak-Kulpa, H. et al. Vitamin K status in peritoneally dialyzed patients with chronic kidney disease. Acta Biochim. Pol. 58, 617-620 (2011).

11. Nicolaidou, P. et al. The effect of vitamin K supplementation on biochemical markers of bone formation in children and adolescents with cystic fibrosis. Eur. J. Pediatr. 165, 540-545 (2006).

12. Dougherty, K. A., Schall, J. I. \& Stallings, V. A. Suboptimal vitamin K status despite supplementation in children and young adults with cystic fibrosis. Am. J. Clin. Nutr. 92, 660-667 (2010)

13. Nowak, J., Lochocka, K. \& Drzymala-Czyz, S. The effects of vitamin K insufficiency induced by oral anticoagulation. Med. News 82, 472-473 (2013).

14. Kuwabara, A. et al. Hypovitaminosis D and $\mathrm{K}$ are highly prevalent and independent of overall malnutrition in the institutionalized elderly. Asia Pac. J. Clin. Nutr. 19, 49-56 (2010).

15. Krasinski, S. D. et al. The prevalence of vitamin K deficiency in chronic gastrointestinal disorders. Am. J. Clin. Nutr. 41, 639-643 (1985).

16. Kuwabara, A. et al. High prevalence of vitamin K and D deficiency and decreased BMD in inflammatory bowel disease. Osteoporos. Int. J. Establ. Result Coop. Eur. Found. Osteoporos. Natl. Osteoporos. Found. USA 20, 935-942 (2009).

17. Nakajima, S. et al. Association of vitamin $\mathrm{K}$ deficiency with bone metabolism and clinical disease activity in inflammatory bowel disease. Nutr. Burbank Los Angel. Cty. Calif 27, 1023-1028 (2011).

18. Shearer, M. J. et al. Mechanism of cephalosporin-induced hypoprothrombinemia: relation to cephalosporin side chain, vitamin K metabolism, and vitamin K status. J. Clin. Pharmacol. 28, 88-95 (1988).

19. Bhat, R. V. \& Deshmukh, C. T. A study of Vitamin K status in children on prolonged antibiotic therapy. Indian Pediatr. 40, 36-40 (2003).

20. Wong, R. S. M., Cheng, G., Chan, N. P. H., Wong, W.-S. \& NG, M. H. L. Use of cefoperazone still needs a caution for bleeding from induced vitamin $\mathrm{K}$ deficiency. Am. J. Hematol. 81, 76 (2006).

21. Shea, M. K. et al. Vitamin K and vitamin D status: associations with inflammatory markers in the Framingham Offspring Study. Am. J. Epidemiol. 167, 313-320 (2008)

22. IBD Working Group of the European Society for Paediatric Gastroenterology, Hepatology and Nutrition. Inflammatory bowel disease in children and adolescents: recommendations for diagnosis-the Porto criteria. J. Pediatr. Gastroenterol. Nutr. 41, 1-7 (2005).

23. Van Assche, G. et al. The second European evidence-based Consensus on the diagnosis and management of Crohn's disease: Definitions and diagnosis. J. Crohns Colitis 4, 7-27 (2010).

24. Turner, D. et al. Development, validation, and evaluation of a pediatric ulcerative colitis activity index: a prospective multicenter study. Gastroenterology 133, 423-432 (2007)

25. Hyams, J. S. et al. Development and validation of a pediatric Crohn's disease activity index. J. Pediatr. Gastroenterol. Nutr. 12, 439-447 (1991).

26. Mahadevan, U. et al. Azathioprine or 6-mercaptopurine before colectomy for ulcerative colitis is not associated with increased postoperative complications. Inflamm. Bowel Dis. 8, 311-316 (2002).

27. Krawczynski, M., Krzyzaniak, A. \& Walkowiak, J. Developmental standards of body height and weight in children and adolescents between 3-18 years of age in the city of Poznań. Pediat. Prakt. 8, 341-353 (2000).

28. Chawla, D. et al. Vitamin K1 versus vitamin K3 for prevention of subclinical vitamin deficiency: a randomized controlled trial. Indian Pediatr. 44, 817-822 (2007).

\section{Acknowledgments}

Supported, in part, by a grant from Poznan University of Medical Sciences.

\section{Author contributions}

J.K.N. performed the statistical analysis, took part in data interpretation and drafted the manuscript. U.G.C., P.L., A.S.P., B.K., and T.B. provided the data and revised the manuscript. T.B., A.P., and D.A. took part in data interpretation and revised the manuscript. J.W. designed the study, coordinated data acquisition, analyzed and interpreted the data, drafted and revised the manuscript. All authors read and approved the final manuscript.

\section{Additional information}

Competing Financial Interests: J.K.N. and J.W. had national conference fees and associated travel costs covered by Merck Sharp \& Dohme.

How to cite this article: Nowak, J.K. et al. Prevalence and correlates of vitamin K deficiency in children with inflammatory bowel disease. Sci. Rep. 4, 4768; DOI:10.1038/srep04768 (2014).

This work is licensed under a Creative Commons Attribution-NonCommercialNoDerivs 3.0 Unported License. The images in this article are included in the article's Creative Commons license, unless indicated otherwise in the image credit; if the image is not included under the Creative Commons license, users will need to obtain permission from the license holder in order to reproduce the image. To view a copy of this license, visit http://creativecommons.org/licenses/by-nc-nd/3.0/ 